\title{
Efeito de produtos químicos e temperaturas de armazenamento na pós-colheita de maracujá-amarelo
}

\section{Postharvest of yellow passion fruit: effect of chemicals and storage temperature}

\author{
Maria Cecília de Arruda ${ }^{1 *}$; Ivan Herman Fischer ${ }^{1}$; Elisangela Marques Jeronimo²; \\ Michele Moraes Zanette ${ }^{3}$; Bruna Lourenço da Silva ${ }^{3}$
}

\begin{abstract}
Resumo
Este trabalho teve como objetivo avaliar o efeito de produtos químicos e de temperaturas de armazenamento na incidência de doenças e na qualidade físico-química de maracujá-amarelo. Frutos colhidos com $30 \%$ da superfície da casca amarela foram tratados com diferentes produtos: dicloroisocianurato de sódio (200 mg. $\mathrm{L}^{-1}$ de cloro ativo); procloraz (1000 mg.L-1); controle (frutos sem tratamento). Os tratamentos foram aplicados por imersão durante três minutos. Os frutos foram acondicionados em embalagem de poliestireno expandido revestida por PVC $17 \mu \mathrm{m}$ e armazenados a 15 e $25^{\circ} \mathrm{C}$, UR $55 \%$, por um período de 10 dias. Os mesmos foram analisados periodicamente quanto à: incidência de podridões, cor da casca, sólidos soluvéis totais, acidez titulável e teor de ácido ascórbico. A incidência de podridões e de crescimento micelial visível no pedúnculo foi crescente conforme o tempo de armazenamento. Após cinco dias o crescimento micelial foi superior nos frutos armazenados à $25^{\circ} \mathrm{C}$ em relação à $15^{\circ} \mathrm{C}$. A aplicação do fungicida procloraz proporcionou redução no surgimento de podridões após dez dias de armazenamento dos frutos. Os principais gêneros fúngicos encontrados nos pedúnculos foram Cladosporium, Alternaria e Fusarium. Constatou-se redução da acidez no décimo dia de armazenamento, cujos teores foram menores nos frutos a $25^{\circ} \mathrm{C}$. Quanto à cor da casca houve redução do ângulo de cor durante o armazenamento, indicando amarelecimento da casca, sendo que os frutos armazenados a $25^{\circ} \mathrm{C}$ apresentaram menor ângulo de cor. Os teores de ácido ascórbico dos frutos reduziram aproximadamente $10 \%$ durante o armazenamento. O ratio (sólidos soluvéis: acidez) aumentou durante o armazenamento, sendo maior nos frutos a $25^{\circ} \mathrm{C}$, decorrente da menor acidez. Conclui-se que o procloraz foi eficiente no controle das podridões e que a utilização dos produtos químicos não influenciou a qualidade físico-química dos frutos embalados. Mudanças nas características físico-químicas foram observadas em função da temperatura e do tempo de armazenamento.
\end{abstract}

Palavras-chave: Passiflora edulis, doenças, qualidade

\begin{abstract}
This study aimed to evaluate the effect of chemicals and storage temperatures on the incidence of diseases and the physicochemical quality of yellow passion fruit. Fruits were harvested with $30 \%$ of the skin colored yellow and treated with different products: sodium dichloroisocyanurate $\left(200 \mathrm{mg} . \mathrm{L}^{-1}\right.$ of active chlorine), prochloraz (1000 mg. $\left.\mathrm{L}^{-1}\right)$, control (fruits not treated). Treatments were applied by immersion for three minutes. The fruits were packed in expanded polystyrene trays coated with PVC $17 \mu \mathrm{m}$ and stored at 15 and $25^{\circ} \mathrm{C}, 55 \% \mathrm{RH}$ for 10 days and analyzed periodically for: rot incidence,

\footnotetext{
${ }^{1}$ Pesquisador Científico da APTA, Pólo Centro Oeste, Bauru, SP. E-mail: mcarruda@apta.sp.gov.br; ihfische@apta.sp.gov.br

${ }^{2}$ Pesquisador Científico da APTA, Pólo Centro Oeste, Unidade de Pesquisa de Jaú, SP. E-mail: elijeronimo@apta.sp.gov.br

${ }^{3}$ Alunas do curso de Ciências Biológicas da Universidade do Sagrado Coração, Bauru, SP. E-mail: michelecatita@yahoo.com.br, lourencobruna@yahoo.com.br

* Autor para correspondência
} 
skin color, soluble solids, titratable acidity and ascorbic acid content. After five days of storage the visible stem mycelial growth was higher in fruits stored at $25^{\circ} \mathrm{C}$ than at $15^{\circ} \mathrm{C}$. The fungicide prochloraz reduced the appearance of rots after ten days of storage fruit. The main fungal genera found in the stems were Cladosporium, Alternaria and Fusarium. Reduction of acidity was observed on the tenth day of storage, and found lower levels of acidity in fruits at $25^{\circ} \mathrm{C}$. Regarding the skin color, reduction in the angle of color during storage indicating yellowing of skin, and the fruits stored at $25^{\circ} \mathrm{C}$ showed a lower angle of color. The levels of ascorbic acid in fruit decreased approximately $10 \%$ during storage. The "ratio" (soluble solids: acidity) increased during storage, being higher in fruits at $25^{\circ} \mathrm{C}$, due to lower acidity. It is concluded that prochloraz was effective in controlling rots and that the use of chemicals not influence the physicochemical quality of packaged fruits. Changes of physicochemical characteristics were observed depending on temperature and time of storage.

Key words: Passiflora edulis, diseases, quality

\section{Introdução}

Um dos principais problemas do maracujá após a colheita é a ocorrência de doenças, sendo a antracnose (Colletotrichum gloeosporioides Penz) considerada a mais importante, responsável por reduzir o período de conservação dos frutos tanto em maracujá-amarelo como maracujá-doce (FISCHER; RESENDE, 2008). O emprego de técnicas que auxiliem na contenção deste problema é bastante desejável. Benato et al. (2002) avaliaram o efeito de fungicidas e outros produtos alternativos no controle de podridões pós-colheita em maracujáamarelo, sob condições ambiente de armazenamento e verificaram maior efetividade dos fungicidas procloraz e imazalil, mas também obtiveram bons resultados com cloreto de benzalcônico, biomassa cítrica e dióxido de cloro.

$\mathrm{Na}$ comercialização de frutas existe demanda crescente por embalagens, cuja utilização, além de valorizar a aparência do produto oferece maior proteção mecânica e fisiológica, diminuindo danos e auxiliando no prolongamento da vida útil destes produtos, especialmente para exportação. Resende; Vilas Boas e Chitarra (2001) verificaram que a utilização de filme de PVC $0,015 \mathrm{~mm}$ associado a benomil P.C (100 mg/L) e absorvedor de etileno propiciou a conservação do maracujá-amarelo em condições excelentes de comercialização até o $35^{\circ}$ dia de armazenamento a $10^{\circ} \mathrm{C}$. Destaca-se, entretanto, que o fungicida benomil deixou de ser comercializado no Brasil a partir de 2007, sendo seu uso e comercialização proibidos pelo Ministério da Agricultura (AGROFIT, 2009).
A redução da temperatura do produto ainda é um dos meios mais eficazes para a manutenção da qualidade, por diminuir a atividade respiratória, retardar a atividade metabólica e inibir o crescimento microbiano, os quais conduzem ao amadurecimento e/ ou à senescência dos tecidos vegetais (CHITARRA; CHITARRA, 2005). Entretanto, atualmente há demanda de informações a respeito da associação temperatura de armazenamento e produtos químicos na ocorrência de doenças em maracujás.

Diante disso, este trabalho visou avaliar o efeito de produtos químicos e de temperaturas de armazenamento na incidência de doenças e na qualidade físico-química de maracujá-amarelo embalado em PVC.

\section{Material e Métodos}

Frutos de maracujá-amarelo variedade 'Afruvec' foram colhidos na região de Bauru/ $\mathrm{SP}$, com base na coloração da casca $(30 \%$ da superfície da casca amarela), ausência de defeitos e com aproximadamente $2 \mathrm{~cm}$ de pedúnculo. Após a colheita os frutos foram transportados ao laboratório da APTA/Bauru e tratados com diferentes produtos, constituindo os tratamentos: a) dicloroisocianurato de sódio (200 mg. $\mathrm{L}^{-1}$ de cloro ativo); b) procloraz (1000 mg.L $\left.\mathrm{L}^{-1}\right)$; c) controle (frutos sem tratamento). Os tratamentos foram aplicados por imersão durante três minutos. Após secagem ao ar, os frutos foram acondicionados em embalagem de poliestireno 
expandido $21 \times 14 \mathrm{~cm}$ revestida por PVC $17 \mu \mathrm{m}$ e armazenados a 15 e $25^{\circ} \mathrm{C}, 55 \%$ de UR, durante 10 dias, sendo avaliados no dia da colheita e no $5^{\circ}$ e $10^{\circ}$ dia de armazenamento quanto à:

a) incidência (\%) de doenças pós-colheita: obtida a partir do número de frutos com sintomas visuais de podridões. Os patógenos incidentes foram identificados por análise morfológica de suas estruturas.

b) incidência (\%) de crescimento micelial no pedúnculo: obtida a partir do número de frutos com crescimento micelial visível. Os gêneros fúngicos foram identificados por análise morfológica de suas estruturas.

c) coloração da casca: determinada pelo ângulo de cor $\left({ }^{\circ} \mathrm{h}\right)$ em colorímetro Minolta CR-400, tomandose duas leituras, em lados opostos, na região de maior diâmetro do fruto. O ângulo de cor $\left({ }^{\circ} h\right)$ define a coloração básica, onde $0^{\circ}=$ vermelho, $90^{\circ}=$ amarelo e $180^{\circ}=$ verde (McGUIRRE, 1992).

d) sólidos soluvéis totais: leitura direta em refratômetro digital com correção automática de temperatura, sendo os resultados expressos em ${ }^{\circ}$ Brix.

e) acidez titulável: por meio de titulação com $\mathrm{NaOH}$, de acordo com metodologia descrita por Carvalho et al. (1990), sendo os resultados expressos em \% acidez.

f) teor de ácido ascórbico: por meio de titulação com DCFI (2.6 diclorofenol indofenol de sódio), de acordo com metodologia descrita por Carvalho et al. (1990). Os resultados foram expressos em mg $100 \mathrm{~g}^{-1}$.

g) Ratio: obtido por meio da razão entre o teor de sólidos solúveis e acidez titulável.

O delineamento utilizado foi inteiramente casualizado em esquema fatorial 3 × 2 × 3 (3 níveis de fator químico: controle, dicloisocianurato de sódio e procloraz; 2 níveis do fator temperatura: 5 e $15^{\circ} \mathrm{C}$ e 3 níveis do fator tempo: 0,5 e 10 dias de armazenamento). Utilizaram-se cinco repetições, sendo cada repetição representada por uma bandeja contendo dois frutos.

Compararam-se as incidências das doenças póscolheita e crescimento micelial (gêneros fúngicos) para cada período de armazenamento por meio de teste não paramétrico de comparação de múltiplas proporções, ao nível de $5 \%$ de probabilidade, conforme descrito por Zar (1999). Os resultados da análise físico-química foram submetidos à análise de variância e as médias comparadas pelo teste de Tukey (5\%).

\section{Resultados e Discussão}

\section{Incidência de doenças}

Não foram observadas diferenças significativas do ponto de vista estatístico entre os tratamentos com produtos químicos na incidência de podridões em frutos de maracujá amarelo acondicionados em embalagem revestida por PVC, aos cinco dias de armazenamento (Tabela 1). Aos dez dias de armazenamento a $15^{\circ} \mathrm{C}$ o fungicida procloraz propiciou redução na incidência de podridões, corroborando com os resultados obtidos por Benato et al. (2002). Não foram observadas diferenças significativas entre os tratamentos em função da temperatura de armazenamento, embora numericamente a incidência de podridões tenha sido igual ou inferior na menor temperatura, relacionado possivelmente ao menor metabolismo, tanto do fruto como dos patógenos (CHITARRA; CHITARRA, 2005). De maneira geral, a incidência de podridões foi crescente durante $o$ armazenamento. A antracnose foi a principal doença pós-colheita em maracujá-amarelo, representando a totalidade de podridões aos cinco dias de armazenamento. Aos dez dias de armazenamento houve ocorrência dos fungos Colletotrichum, Phomopsis e Fusarium. Em estudo comparativo entre maracujá-amarelo produzido em sistema orgânico e convencional, antracnose também foi a doença mais importante, seguida pelas podridões de fusarium e phomopsis (FISCHER et al., 2007). 
Tabela 1. Podridão (\%) de frutos de maracujá-amarelo tratados com produtos químicos e acondicionados em embalagem revestida por filme de PVC, ao quinto e décimo dia de armazenamento a 15 e $25^{\circ} \mathrm{C}$.

\begin{tabular}{lcccc}
\hline Tratamentos $^{\mathbf{1}}$ & \multicolumn{2}{c}{$\mathbf{5}$ dias } & \multicolumn{2}{c}{$\mathbf{1 0}$ dias } \\
\cline { 2 - 5 } & $15^{\circ} \mathrm{C}$ & $25^{\circ} \mathrm{C}$ & $65^{\circ} \mathrm{C}$ & $25^{\circ} \mathrm{C}$ \\
\hline PVC & $10 \mathrm{aA}^{2}$ & $50 \mathrm{aA}$ & $60 \mathrm{aA}$ & $60 \mathrm{aA}$ \\
PVC+procloraz & $10 \mathrm{aA}$ & $20 \mathrm{aA}$ & $10 \mathrm{aB}$ & $40 \mathrm{aA}$ \\
PVC+dicloroisocianurato $\mathrm{Na}$ & $30 \mathrm{aA}$ & $50 \mathrm{aA}$ & $60 \mathrm{aA}$ & $70 \mathrm{aA}$ \\
\hline
\end{tabular}

${ }^{1}$ Total de 10 frutos.

${ }^{2}$ Médias seguidas pela mesma letra minúscula na linha e maiúscula na coluna, não diferem entre si para cada período de armazenamento, em nível de $5 \%$ pelo teste não paramétrico de comparação de múltiplas proporções.

A incidência de frutos de maracujá-amarelo com crescimento micelial no pedúnculo (Tabela 2), assim como a frequência total de gêneros fúngicos (Tabela 3) foi superior nos frutos armazenados a $25^{\circ} \mathrm{C}$, comparado a $15^{\circ} \mathrm{C}$ após cinco dias de armazenamento. Com dez dias de armazenamento todos os frutos apresentaram crescimento micelial visível nos pedúnculos. O tratamento dos frutos com procloraz ou dicloroisocianurato de sódio não inibiu o crescimento micelial no pedúnculo do maracujá. Os principais gêneros fúngicos encontrados nos pedúnculos foram Cladosporium, Alternaria e Fusarium. Segundo Palou et al. (2001), Cladosporium e Alternaria também foram os gêneros fúngicos mais freqüentes em levantamento da micoflora epífita de frutos cítricos. Aos dez dias de armazenamento não foram observadas diferenças na frequência total de gêneros fúngicos em função dos tratamentos e temperatura de armazenamento, sendo observados, em adição aos gêneros fúngicos observados no quinto dia (Tabela 3), os gêneros Aspergillus, Lasiodiplodia, Neurospora e Rhizopus.

Tabela 2. Crescimento micelial (\%) no pedúnculo de frutos de maracujá-amarelo tratados com produtos químicos e acondicionados em embalagem revestida por filme de $\mathrm{PVC}$, ao quinto e décimo dia de armazenamento a 15 e $25^{\circ} \mathrm{C}$.

\begin{tabular}{lcccc}
\hline Tratamentos $^{1}$ & \multicolumn{2}{c}{$\mathbf{5}$ dias } & \multicolumn{2}{c}{$\mathbf{1 0}$ dias } \\
\cline { 2 - 5 } & $15^{\circ} \mathrm{C}$ & $25^{\circ} \mathrm{C}$ & $15^{\circ} \mathrm{C}$ & $25^{\circ} \mathrm{C}$ \\
\hline PVC & $20 \mathrm{aA}^{2}$ & $100 \mathrm{bA}$ & $100 \mathrm{aA}$ & $100 \mathrm{aA}$ \\
PVC+procloraz & $00 \mathrm{aA}$ & $80 \mathrm{bA}$ & $100 \mathrm{aA}$ & $100 \mathrm{aA}$ \\
PVC+dicloroisocianurato $\mathrm{Na}$ & $40 \mathrm{aA}$ & $100 \mathrm{bA}$ & $100 \mathrm{aA}$ & $100 \mathrm{aA}$ \\
\hline
\end{tabular}

${ }^{1}$ Total de 10 frutos.

${ }^{2}$ Médias seguidas pela mesma letra minúscula na linha e maiúscula na coluna, não diferem entre si para cada período de armazenamento, em nível de 5 \% pelo teste não paramétrico de comparação de múltiplas proporções.

\section{Qualidade físico-química}

A qualidade físico-química dos frutos não foi afetada pelos tratamentos químicos, mas sim, pela temperatura e tempo de armazenamento, na maioria das variáveis avaliadas, exceto o teor de sólidos solúveis que não foi afetado por nenhum fator. Uma vez que os tratamentos químicos não influenciaram na qualidade físico-química, optou-se por apresentar os valores médios obtidos entre os tratamentos. 
Tabela 3. Frequência dos gêneros fúngicos encontrados no pedúnculo de frutos de maracujá-amarelo tratados com produtos químicos e acondicionados em embalagem revestida por filme de PVC, ao quinto dia de armazenamento a 15 e $25^{\circ} \mathrm{C}$.

\begin{tabular}{|c|c|c|c|c|c|c|c|}
\hline \multirow[t]{2}{*}{ Tratamentos $^{1}$} & \multicolumn{7}{|c|}{ Gêneros fúngicos } \\
\hline & Alternaria & Cladosporium & Fusarium & Penicillium & Colletotrichum & Cephalosporium & Total \\
\hline \multicolumn{8}{|c|}{$15^{\circ} \mathrm{C}$} \\
\hline PVC & 2 & 1 & 0 & 0 & 0 & 0 & $3 \mathrm{ab}^{2}$ \\
\hline $\mathrm{PVC}+$ procloraz & 0 & 0 & 0 & 0 & 0 & 0 & $0 \mathrm{a}$ \\
\hline $\begin{array}{l}\mathrm{PVC}+ \\
\text { dicloroisocianurato } \mathrm{Na}\end{array}$ & 2 & 2 & 1 & 0 & 1 & 0 & $6 \mathrm{~b}$ \\
\hline Média & 1,3 & 1,0 & 0,3 & 0 & 0,3 & 0 & \\
\hline \multicolumn{8}{|c|}{$25^{\circ} \mathrm{C}$} \\
\hline PVC & 4 & 10 & 1 & 2 & 0 & 0 & $17 \mathrm{a}$ \\
\hline PVC+procloraz & 6 & 7 & 3 & 1 & 0 & 0 & $17 \mathrm{a}$ \\
\hline $\begin{array}{l}\mathrm{PVC}+ \\
\text { dicloroisocianurato } \mathrm{Na}\end{array}$ & 6 & 7 & 4 & 1 & 0 & 2 & $20 \mathrm{a}$ \\
\hline Média & 5,3 & 8,0 & 2,7 & 1,3 & 0 & 0,7 & \\
\hline
\end{tabular}

${ }^{1}$ Total de 10 frutos.

${ }^{2}$ Médias seguidas pela mesma letra minúscula na coluna não diferem entre si para cada temperatura, em nível de $5 \%$ pelo teste não paramétrico de comparação de múltiplas proporções.

Embora a coloração da casca dos frutos tenha diferido $(\mathrm{P}<0,05)$ em função da temperatura, a variação foi quantitativamente pequena (Tabela 4), não evidenciada visualmente. O ângulo de cor reduziu em função do tempo de armazenamento (Tabela 5), mostrando amarelecimento da casca.
A perda da cor verde deve-se à decomposição da clorofila. Esse processo é causado por mais de um fator que pode atuar em conjunto ou isoladamente. São eles: alteração de $\mathrm{pH}$, atividade de enzimas (clorofilase), presença de sistemas oxidantes (enzimáticos ou químicos) (JACOMINO et al., 2008).

Tabela 4. Características físico-químicas de maracujá-amarelo em função da temperatura de armazenamento.

\begin{tabular}{cccccc}
\hline \multirow{2}{*}{ Temperaturas de armazenamento } & \multicolumn{5}{c}{ Variáveis analisadas $^{2}$} \\
\cline { 2 - 6 } & Cor & SS & AT & Ratio & AA \\
\hline $15^{\circ} \mathrm{C}$ & $102,98 \mathrm{a}^{1}$ & $12,93 \mathrm{a}$ & $3,54 \mathrm{a}$ & $3,69 \mathrm{~b}$ & $18,88 \mathrm{a}$ \\
$25^{\circ} \mathrm{C}$ & $101,34 \mathrm{~b}$ & $12,68 \mathrm{a}$ & $3,31 \mathrm{~b}$ & $3,90 \mathrm{a}$ & $18,78 \mathrm{a}$ \\
\hline
\end{tabular}

${ }^{1}$ Médias seguidas de mesma letra na coluna não diferem entr si, pelo teste de Tukey ao nível de 5\% e probabilidade.

${ }^{2}$ Cor da casca $\left({ }^{\circ}\right.$ h); SS: sólidos solúveis ( ${ }^{\circ}$ Brix); AT: acidez titulável (\% ácido cítrico); Ratio: relação obtida entre sólidos solúveis e acidez; AA: ácido ascórbico $\left(\mathrm{mg} .100 \mathrm{~g}^{-1}\right)$.

Houve redução do teor de acidez titulável em função do aumento da temperatura (Tabela 4) e ao longo do período de armazenamento (Tabela 5). A diminuição do teor de sólidos solúveis e de acidez titulável geralmente está associada ao consumo destes compostos no processo respiratório (CHITARRA; CHITARRA, 2005). 
Tabela 5. Características físico-químicas de maracujá-amarelo em função do tempo de armazenamento.

\begin{tabular}{cccccc}
\hline \multirow{2}{*}{ Tempos de armazenamento } & \multicolumn{5}{c}{ Variáveis analisadas $^{2}$} \\
\cline { 2 - 6 } & Cor & SS & AT & Ratio & AA \\
\hline 0 & $104,40 \mathrm{a}^{1}$ & $12,98 \mathrm{a}$ & $3,50 \mathrm{a}$ & $3,72 \mathrm{ab}$ & $20,37 \mathrm{a}$ \\
5 & $102,71 \mathrm{~b}$ & $12,87 \mathrm{a}$ & $3,57 \mathrm{a}$ & $3,65 \mathrm{~b}$ & $18,14 \mathrm{~b}$ \\
10 & $99,37 \mathrm{c}$ & $12,56 \mathrm{a}$ & $3,19 \mathrm{~b}$ & $4,00 \mathrm{a}$ & $17,97 \mathrm{~b}$ \\
\hline
\end{tabular}

${ }^{1}$ Médias seguidas de mesma letra na coluna não diferem entr si, pelo teste de Tukey ao nível de 5\% e probabilidade.

${ }^{2}$ Cor da casca $\left({ }^{\circ} \mathrm{h}\right)$; SS: sólidos solúveis ( $\left.{ }^{\circ} \mathrm{Brix}\right)$; AT: acidez titulável (\% ácido cítrico); Ratio: relação obtida entre sólidos solúveis e acidez; AA: ácido ascórbico (mg.100g-1).

$\mathrm{O}$ menor teor de acidez a $25^{\circ} \mathrm{C}$ reflete a maior atividade metabólica com o aumento da temperatura. De uma maneira geral, a velocidade das reações biológicas de um produto colhido aumenta de duas a três vezes para cada $10^{\circ} \mathrm{C}$ de aumento de temperatura (KLUGE et al., 2002).

O teor de sólidos solúveis dos frutos não foi influenciado por nenhum fator estudado. Salazar e Torres (1977) e Gama et al. (1991) também verficaram manutenção do teor de sólidos solúveis e redução da acidez durante armazenamento de maracujá-amarelo.

O teor de ácido ascórbico foi influenciado apenas pelo tempo de armazenamento, sendo verificado redução de aproximadamente $10 \%$ ao final de 10 dias. Redução do teor de ácido ascórbico foi verificada em maracujá-amarelo por Salazar e Torres (1977) e Cereda et al. (1984). A redução do ácido ascórbico deve-se à oxidação deste composto por uma série de mecanismos químicos e bioquímicos. Diferentes enzimas estão relacionadas com sua degradação, entre elas: ácido ascórbico oxidase, peroxidase, polifenoloxidase e citocromo oxidase (CHITARRA, 1998).

\section{Conclusões}

A aplicação de procloraz foi eficiente no controle das podridões avaliadas.

A utilização dos produtos químicos não influenciou a qualidade físico-química dos frutos embalados.
Alterações nas características físico-químicas resultaram do efeito da temperatura de $25{ }^{\circ} \mathrm{C}$ e do tempo de armazenamento (10 dias).

\section{Referências}

AGROFIT. Sistemas de agrotóxicos fitossanitários. Brasília: Ministério da Agricultura, Pecuária e Abastecimento. 2009. Disponível em: <http://extranet. agricultura.gov.br/agrofit_cons/principal_agrofit_cons $>$. Acesso em: 21 jun. 2009.

BENATO, E. A.; SIGRIST, J. M.; HANASHIRO, M. M.; MAGALHÃES, M. J. M.; BINOTTI, C. Avaliação de fungicidas e produtos alternativos no controle de podridões pós-colheita em maracujá-amarelo. Summa Phytopathologica, Botucatu, v. 28, n. 4, p. 299-304, 2002.

CARVALHO, C. R. L.; MANTOVANI, D. M. B.; CARVAlHO, P. R. N.; MORAES, R. M. M. Análise química de alimentos. Campinas: ITAL, 1990. $121 \mathrm{p}$.

CEREDA, E.; LIMA, U. A.; CUNHA, R. J. P.; CEREDA, M. P. Conservação e armazenamento do maracujá amarelo Passiflora edulis f. flavicarpa Deg. III - variações no teor de ácido ascórbico. Turrialba, San José, v. 34, n. 4, p. 517-523, 1984.

CHITARRA, M. I. F. Processamento mínimo de frutos e hortaliças. Viçosa: Centro de Produções Técnicas, 1998. $88 \mathrm{p}$.

CHITARRA, M. I. F.; CHITARRA, A. B. Pós-colheita de frutos e hortaliças: fisiologia e manuseio. 2. ed. Lavras: UFLA, 2005. $785 \mathrm{p}$.

FISCHER, I. H.; ARRUDA, M. C.; ALMEIDA, A. M.; GARCIA, M. J. M.; JERÔNIMO, E. M.; PINOTTI, R. N.; BERTANI, R. M. A. Doenças e características físicas e químicas pós-colheita em maracujá amarelo de cultivo convencional e orgânico no Centro Oeste Paulista. Revista Brasileira de Fruticultura, Jaboticabal, v. 29, n. 2, p. 254-259, 2007. 
FISCHER, I. H.; RESENDE, J. A. M. Diseases of passion flower (Passiflora spp.). Pest Technology, Kagawa, v. 2, n. 1, p. 1-19, 2008.

GAMA, F. S. N. da.; MANICA, I.; KIST, H. G. K.; ACCORSI, M. R. Aditivos e embalagens de polietileno na conservação do maracujá amarelo armazenado em condições de refrigeração. Pesquisa Agropecuária Brasileira, Brasília, v. 26, n. 3, p. 305-310, 1991.

JACOMINO, A. P.; ARRUDA, M. C. de.; BRON, I. U.; KLUGE, R. A. Transformações bioquímicas em produtos hortícolas após a colheita. In: KOBLITZ, M. G. B. (Coord.). Bioquímica de alimentos - teoria e aplicações práticas. Rio de Janeiro: Guanabara Koogan, 2008. cap. 6, p. 153-189.

KLUGE, R. A.; NACHTIGAL, J. C.; FACHINELLO, J. C.; BILHALVA, A. B. Fisiologia e manejo pós-colheita de frutas de clima temperado. Campinas: Livraria e Editora Rural, 2002. 214 p.
McGUIRRE, R. G. Reporting of objective color measurents. HortScience, Alexandria, v. 27, n. 12, p. 1254-1255, 1992.

PALOU, L.; USALL, J.; PONS, J.; VIÑAS, I. Micoflora epifita de los frutos y ambiental en campos de mandarino 'Clemenules' en Tarragona. Revista Investigación Agraria: Production Protección Vegetal, Madrid, v. 16, n. 2, p. 257-272, 2001.

RESENDE, J. M.; VILAS BOAS, E. V. B.; CHITARRA, M. I. F. Uso de atmosfera modificada na conservação póscolheita do maracujá amarelo. Ciência e Agrotecnologia, Lavras, v. 25, n. 1, p. 159-168, 2001.

SALAZAR, R.; TORRES, R. Almacenamiento de frutos de maracuya (Passiflora edulis var. flavicarpa, Degener) en bolsas de polietileno. Revista ICA, Bogotá, v. 12, n. 1, p. 1-11, 1977.

ZAR, J. H. More on dichotomus variables. In: Biostatistical analyis. New Jersey: Prentice-Hall, 1999. p. 516-570. 
